Open Access

\title{
Community-level effect of the reproductive health vouchers program on out-of-pocket spending on family planning and safe motherhood services in Kenya
}

Francis Obare ${ }^{1 *}$, Charlotte Warren ${ }^{2}$, Lucy Kanya ${ }^{3}$, Timothy Abuya ${ }^{1}$ and Ben Bellows ${ }^{1}$

\begin{abstract}
Background: Although vouchers can protect individuals in low-income countries from financial catastrophe and impoverishment arising from out-of-pocket expenditures on healthcare, their effectiveness in achieving this goal depends on whether both service and transport costs are subsidized as well as other factors such as service availability in a given locality and community perceptions about the quality of care. This paper examines the community-level effect of the reproductive health vouchers program on out-of-pocket expenditure on family planning, antenatal, delivery and postnatal care services in Kenya.
\end{abstract}

Methods: Data are from two rounds of cross-sectional household surveys in voucher and non-voucher sites. The first survey was conducted between May 2010 and July 2011 among 2,933 women aged 15-49 years while the second survey took place between July and October 2012 among 3,094 women of similar age groups. The effect of the program on out-of-pocket expenditure is determined by difference-in-differences estimation. Analysis entails comparison of changes in proportions, means and medians as well as estimation of multivariate linear regression models with interaction terms between indicators for study site (voucher or non-voucher) and period of study (2010-2011 or 2012).

Results: There were significantly greater declines in the proportions of women from voucher sites that paid for antenatal, delivery and postnatal care services at health facilities compared to those from non-voucher sites. The changes were also consistent with increased uptake of the safe motherhood voucher in intervention sites over time. There was, however, no significant difference in changes in the proportions of women from voucher and non-voucher sites that paid for family planning services. The results further show that there were significant differences in changes in the amount paid for family planning and antenatal care services by women from voucher compared to those from non-voucher sites. Although there were greater declines in the average amount paid for delivery and postnatal care services by women from voucher compared to those from non-voucher sites, the difference-in-differences estimates were not statistically significant.

Conclusions: The reproductive health vouchers program in Kenya significantly contributed to reductions in the proportions of women in the community that paid out-of-pocket for safe motherhood services at health facilities.

\footnotetext{
* Correspondence: fonyango@popcouncil.org

'Reproductive Health Program, Population Council, Ralph Bunche Road, General Accident House, P.O. Box 17643, Nairobi 00500, Kenya

Full list of author information is available at the end of the article
} 


\section{Background Introduction}

In many countries, high out-of-pocket spending on healthcare services prevents some people from seeking care and can result in financial catastrophe and impoverishment for others [1-5]. The problem is particularly pronounced in low-income countries characterized by weak healthcare systems and high out-of-pocket payments due to absence of formal health insurance or other health financing schemes [6-8]. As of 2005, the World Health Organization (WHO) estimated that 44 million households worldwide faced catastrophic expenditures on healthcare (defined as expenditures comprising at least $40 \%$ of a household's nonsubsistence income) and that 25 million households were pushed into poverty as a result [9]. Healthcare financing strategies that combine demand-side subsidies with supplyside incentives have the potential of protecting individuals in low-income countries from financial catastrophe and impoverishment arising from out-of-pocket expenditures on healthcare $[5,10-13]$. The use of reproductive health vouchers is one such approach that aims to reduce the financial barriers to accessing healthcare for the poor, stimulate client demand for services, and give clients the purchasing power to seek care from the full range of available providers [10,14-16]. Reduction in financial barriers is achieved through subsidizing the cost of services, transport to accredited providers, or both.

Effectiveness of voucher programs in reducing out-ofpocket spending for beneficiaries depends on whether both service and transport costs are subsidized as well as other factors such as service availability in a given locality and community perceptions about the quality of care. For instance, distance to care has been found to be a major determinant of uptake of health care services in developing countries $[17,18]$. In such a context, voucher programs may not effectively address barriers to service utilization if they only subsidize clients' out-of-pocket spending on health services without subsidizing transportation costs. Perceptions about the quality of available services are another key determinant of service uptake in developing countries $[8,19,20]$. It is therefore likely that even with a voucher subsidy program in place, clients might continue paying out-of-pocket at facilities that offer better services if they perceive the quality of care offered by accredited providers to be poor.

This paper examines the community-level effect of the reproductive health vouchers program on out-of-pocket spending on services in Kenya. It specifically examines the differences in changes in the likelihood of paying out-of-pocket and in the amount paid for family planning, antenatal care, delivery and postnatal care services at health facilities over time among women from voucher and non-voucher sites. Due to the voucher subsidy, we should expect a greater reduction in the likelihood of paying out-of-pocket and in the amount paid for the services by women from voucher compared to those from non-voucher sites. The premise is that as more women from voucher sites bought and used the voucher, the average out-of-pocket spending at the community level should be lower than in non-voucher sites. The increase in the number of women who did not pay for the services or who paid lower amounts in voucher sites should, in turn, be consistent with increased uptake of the voucher over time. By contrast, given the absence of the voucher subsidy in comparison sites, there should be no major change in the pool of women at the community level who did not pay or in the amount paid for the services at health facilities.

\section{Healthcare expenditure in Kenya}

The percentage of gross domestic product (GDP) spent on healthcare in Kenya fluctuated between $4.1 \%$ and $4.5 \%$ over the one and half decades covering the period 1996 to 2011 (Table 1). By contrast, the percentage of GDP spent on healthcare in Uganda steadily increased over the same period from $5.5 \%$ in 1996 to $9.5 \%$ in 2011 while in Tanzania, the percentage of GDP spent on healthcare steadily increased between 2005 and 2011 (from $4.0 \%$ to $7.3 \%$ ) after nearly a decade of stagnation at about $3 \%$ (Table 1). During the same period, the

Table 1 Healthcare expenditure as percentage of gross domestic product and government spending on healthcare as percentage of general government expenditure in Kenya, Uganda and Tanzania, 1996-2011

\begin{tabular}{|c|c|c|c|c|c|c|}
\hline \multirow[t]{2}{*}{ Year } & \multicolumn{3}{|c|}{$\begin{array}{l}\text { Healthcare expenditure as percentage of gross domestic } \\
\text { product (\%) }\end{array}$} & \multicolumn{3}{|c|}{$\begin{array}{l}\text { Government spending on healthcare as percentage of general governmen } \\
\text { expenditure (\%) }\end{array}$} \\
\hline & Kenya & Uganda & Tanzania & Kenya & Uganda & Tanzania \\
\hline 1996 & 4.1 & 5.5 & 3.4 & 7.3 & 9.8 & 10.2 \\
\hline 1999 & 4.2 & 6.7 & 3.2 & 8.3 & 11.3 & 10.2 \\
\hline 2002 & 4.5 & 7.5 & 3.4 & 8.3 & 9.7 & 11.1 \\
\hline 2005 & 4.4 & 9.2 & 4.0 & 7.6 & 11.2 & 8.7 \\
\hline 2008 & 4.2 & 8.8 & 5.4 & 6.1 & 9.5 & 16.0 \\
\hline 2011 & 4.5 & 9.5 & 7.3 & 5.9 & 10.8 & 11.1 \\
\hline
\end{tabular}

Source: World Health Organization (2013) Global Health Expenditure Database [35] 
Kenya government spending on healthcare as percentage of general government expenditure fluctuated between $6 \%$ and $8 \%$ and was constantly lower than that of her neighbours, Uganda and Tanzania (Table 1).

In terms of contribution to the total healthcare expenditure, out-of-pocket spending consistently comprised the largest share of total healthcare expenditure in the country over the years. In particular, the percentage of total healthcare expenditure arising from out-ofpocket payments ranged from $42 \%$ in 1996 to $48 \%$ in 1999 while the share of government spending ranged from $39 \%$ in 2008 and 2011 to $43 \%$ in 2012 (Fig. 1). Healthcare spending from other private sources, on the other hand, ranged from $12 \%$ in 1999 and 2002 to $18 \%$ in 1996 (Fig. 1). Available evidence shows that households in Kenya spend about $10 \%$ of their budget on healthcare with the burden being greater among poor than rich households and for outpatient compared to inpatient services [1]. Estimates further show that $5 \%$ of households in Kenya face catastrophic expenditures on health according to WHO definition (expenditures comprising $40 \%$ or higher of non-subsistence income) and that about 1.5 million people in the country are pushed into poverty due to healthcare payments [1].

\section{Kenya reproductive health vouchers program}

The reproductive health vouchers program in Kenya is implemented by the Government with major funding from the German Development Bank (KfW). The objective of the program is to reduce maternal and neonatal mortality through increased health facility delivery and improved access to appropriate health services for the poor by providing incentives for increased demand and improved service provision [21-23]. It was first piloted between 2006 and 2008 in four Counties (Kisumu,
Kiambu, Kitui and Nairobi) with 54 public, private-forprofit and private-not-for-profit health facilities being accredited to provide services to voucher clients. During the second phase (2008-2011), 25 more health facilities from the same Counties were added to the program. The program was further expanded to Kilifi County in Coast region over the same period where 14 additional health facilities were accredited to provide services to voucher clients. The third phase of the program started in late 2011 and entailed accreditation of more health facilities in the same Counties.

The program subsidizes three reproductive health service components. The first component is safe motherhood services comprising four antenatal care visits, delivery care including Caesarean section if needed, postnatal care within six weeks post-delivery, and treatment of neonatal complications. The second component includes long-term family planning methods, namely, implants, intrauterine contraceptive device (IUCD), and voluntary surgical contraception. The third component comprises gender-based violence recovery services. The safe motherhood and family planning vouchers are made available through distributors in the community appointed by the voucher management agency at subsidized costs of KSh. 200 (equivalent US \$2.50) and KSh. 100 (equivalent US \$1.25) respectively. The beneficiaries are identified through the use of a poverty grading tool that consists of eight items on household assets and amenities, expenditure or income, and access to health services that are unique to each County. Women who score between 8 and 16 points on the tool qualify for the vouchers. The gender-based violence recovery services vouchers are, on the other hand, made freely available for clients seeking the services at accredited health facilities. Detailed descriptions of the design of

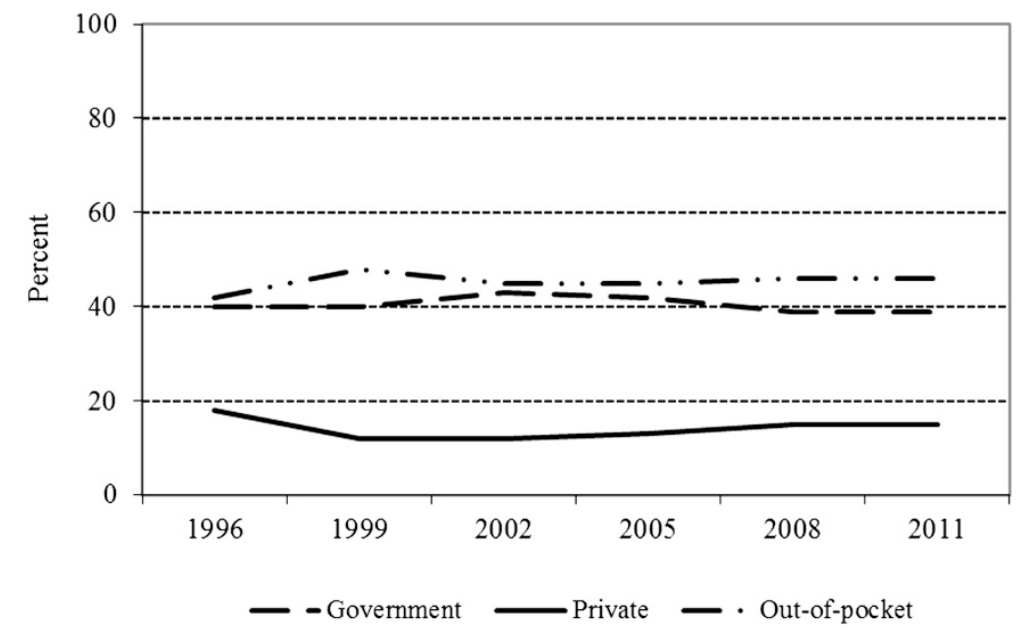

Fig. 1 Healthcare expenditure in Kenya by source, 1996-2011. Source: Computed by the authors from the World Health Organization (2013) Global Health Expenditure Database 
the program are in Hagenmeyer et al. [21], Janisch et al. [24] and RH-OBA Technical Committee [23].

\section{Methods}

\section{Study design}

The study used a quasi-experimental design involving two rounds of cross-sectional household surveys in voucher and non-voucher sites. The design was chosen because there was no random assignment of sites to voucher or comparison group. Rather, voucher sites were identified by the Government in collaboration with the major funding agency based on the prevailing reproductive health indicators and availability of health facilities at the time of program inception. Health facilities in the selected sites were then approached to participate in the program and those that satisfied the accreditation criteria were contracted as voucher service providers. The comparison sites were, on the other hand, identified by the researchers in collaboration with the Ministry of Health based on geographical location (being adjacent to the intervention site), population characteristics, and availability of health facilities similar to those in voucher sites in terms of level (hospital, nursing home, health center, and dispensary) and type of ownership (public, private-for-profit and private-not-for-profit). For instance, if the intervention site had a public referral hospital, the comparison site chosen was the neighboring county that also had such a health facility. The approach was informed by the belief that neighboring counties would have populations with similar characteristics. In addition, populations living near a health facility of a certain level and type should ideally have access to the same type of health care services.

\section{Data}

The first survey was conducted between May 2010 and July 2011 among 2,933 women aged 15-49 years while the second survey took place between July and October 2012 among 3,094 women of similar age groups. Respondents were identified from sub-locations (the smallest administrative units in Kenya) within fivekilometre radius to the health facilities that were accredited to offer services to voucher clients in four of the five program Counties (Kiambu, Kilifi, Kisumu and Kitui) and similar non-contracted facilities (in terms of level and type of ownership) in three comparison sites (Makueni, Nyandarua and Uasin Gishu Counties).

A two-stage sampling process was used. The first stage was a random sample of 14 sub-locations in each County from within five kilometres of the selected health facilities in voucher and comparison sites. Geographical positioning system (GPS) coordinates of the facilities were used to identify sub-locations that provided the sampling frame. The second stage entailed a random sample of three villages from each of the selected sub-locations. In each of the sampled villages, the local administration assisted with identifying the poorest households for inclusion in the study. Interviewers then administered the poverty grading tool that is used by the voucher management agency to target beneficiaries to the identified households to further confirm eligibility. The rationale for using the approach was used to capture as many individuals who would qualify for the vouchers as possible given that vouchers are not randomly assigned to beneficiaries. A total of 400 women $(75 \%$ poor and $25 \%$ non-poor women for comparison) were targeted in each County in order to detect significant differences in key reproductive health indicators between voucher and comparison sites at $95 \%$ confidence level with $80 \%$ power [25]. More poor than non-poor women were targeted in each County in order to increase the chances of interviewing those who had actually used the voucher as opposed to simply qualifying based on the poverty grading scores.

In each selected household, women aged 15-49 years who gave birth in the past 12 months before the survey or were pregnant at the time of the interview were targeted for individual interview. In case the selected household did not have such a member, any female member of reproductive age (15-49 years) who was willing to be interviewed was approached to participate in the study. For households with two or more eligible female members, the youngest was interviewed because they are likely to be more disadvantaged in terms of accessing reproductive health services compared to older women. Respondents provided information on household assets and amenities, health-related household arrangements, food security, household expenditures on goods and services, individual background characteristics (age, education level, religious affiliation, and marital and employment status), general health status and health care utilization, childbearing experiences and intentions, as well as awareness, use and perceptions about vouchers. Women who had given birth in the five years before the survey further provided detailed information on each of the births including whether and where antenatal, delivery, and postnatal care services were sought. In the first survey, women were further asked whether they paid for safe motherhood services for the most recent birth and how much they paid. In the second survey, the questions on payments were asked for each of the births occurring in the five years preceding the survey.

Analysis of payments for safe motherhood services focuses on the most recent live birth occurring within two years before the interview in order to avoid overlap of births across surveys. A total of 951 women reported having a birth in the two years preceding the first survey (590 in voucher and 391 in non-voucher sites) while in the subsequent survey, 1,549 women reported having a 
birth during the reference period (915 in voucher and 634 in non-voucher sites). In both surveys, all women were asked about their knowledge and use of family planning, whether they paid for family planning services the last time they obtained a method, and how much they paid. Analysis of payments for family planning services focuses on women who used a method in the 12 months preceding the survey. The interviews were conducted in Kiswahili, English or the local language after obtaining written informed consent from respondents. The survey tool was pre-tested among a group of women with characteristics similar to those who were targeted for inclusion in the study in order to identify questions that required modification. The study obtained ethical clearance from the Institutional Review Board of the Population Council (Protocol No. 470) and the Ethics Review Committee of the Kenya Medical Research Institute (Protocol No. 174).

\section{Analysis}

Analysis is in two parts and entails difference-in-differences estimation, that is, the difference in changes over time between women from voucher and non-voucher sites [26]. The first part is a comparison of changes in proportions of women who obtained family planning, antenatal, delivery and postnatal care services from health facilities and paid for the care they received as well as the average and median amounts paid over time (in Kenya Shillings) in voucher and non-voucher sites. The second part of the analysis involves estimation of multivariate linear regression models to examine the differences in changes in the proportions paying and the amount paid for family planning and safe motherhood services at health facilities over time between voucher and non-voucher sites. The basic model includes an interaction term between survey year and study site and adjusts for clustering of individuals at the sub-location level. The basic form of the model is specified as follows:

$$
Y_{i j}=\alpha_{0}+\alpha_{1} X_{1 i j}+\alpha_{2} X_{2 i j}+\alpha_{3} X_{1 i j} * X_{2 i j}+\ldots+X_{i j} \beta+\varepsilon_{j}
$$

The parameter $X_{1}$ in Equation (1) is the indicator for study round, $X_{2}$ is the indicator for study site, $X_{i j}$ is the vector of other covariates included in the model for individual $i$ from sub-location $j$, and $\beta$ is the associated vector of fixed parameters. The parameter $\alpha_{0}$ represents the outcome for women from non-voucher sites at baseline (in 2010-2011); $\alpha_{1}$ is the change in the outcome between baseline and follow-up among women from nonvoucher sites; $\alpha_{2}$ is the difference in the outcome between women from voucher and non-voucher sites at baseline; $\alpha_{3}$ represents the difference in the changes in the outcome between women from voucher and non-voucher sites over time (difference-in-differences estimate); and $\varepsilon_{j}$ are the unobserved characteristics of women from the same sub-location that might be correlated with the outcome of interest.

Two sets of models were estimated for each of the reproductive health indicators considered, namely, family planning, antenatal, delivery and postnatal care. The first set of models had a binary outcome of whether the respondents paid for services or not while the outcome for the second set of models was the amount paid for services. The models controlled for education level, marital status, type of place of residence, duration of residence, poverty status, parity, and type of facility where services were sought. In addition, the models for safe motherhood services controlled for maternal age at the time of the most recent birth while the models for family planning services controlled for age of the respondent at the time of interview. Table 2 presents the definitions and measurement of the variables included in both models.

\section{Results}

\section{Characteristics of women}

Across all surveys and study sites, the majority of the women interviewed were aged between 25-34 years, had primary level education, were married or living with a man at the time of the survey, were from rural areas, had lived at the place for five years or more, were poor according to the grading criteria used to identify voucher beneficiaries, and had between one and five children (Table 3). There were, however, significant variations in the distribution of women from voucher and non-voucher sites by age, highest education level, type of place of residence, and poverty status in both surveys. In particular, the proportion of women aged 15-24 years was greater in voucher than in non-voucher sites while the proportion aged 35 years and above was greater in non-voucher than in voucher sites. Similarly, the proportion of women with lower than primary level education was greater in voucher than in non-voucher sites while the proportion with secondary or higher levels of education was greater in non-voucher compared to voucher sites. The proportion living in urban areas and the proportion poor were greater in voucher than in non-voucher sites. In addition, there were significant variations in the distribution of women by duration of residence in the 2010-2011 but not in the 2012 survey.

\section{Use of reproductive health services}

The proportions of women that had ever used any family planning method and the proportions that used a method in the 12 months preceding the survey were significantly higher in non-voucher than in voucher sites in both the 2010-2011 and 2012 surveys (Table 4). There was, however, no significant difference by study site in 
Table 2 Definition and measurement of variables used in multivariate analysis

\begin{tabular}{|c|c|}
\hline Variable definition & Measurement \\
\hline \multicolumn{2}{|l|}{ Outcome variables } \\
\hline \multirow[t]{2}{*}{ Paid for family planning services } & $0=\mathrm{No}$ \\
\hline & $1=$ Yes \\
\hline \multirow[t]{2}{*}{ Paid for antenatal care services } & $0=\mathrm{No}$ \\
\hline & $1=$ Yes \\
\hline \multirow[t]{2}{*}{ Paid for delivery services } & $0=\mathrm{No}$ \\
\hline & $1=$ Yes \\
\hline \multirow{2}{*}{$\begin{array}{l}\text { Paid for postnatal } \\
\text { care services }\end{array}$} & $0=\mathrm{No}$ \\
\hline & $1=$ Yes \\
\hline $\begin{array}{l}\text { Amount paid for } \\
\text { family planning services }\end{array}$ & $\begin{array}{l}\text { Continuous (ranges from KSh. } \\
0 \text { to KSh. } 2,500 \text { ) }\end{array}$ \\
\hline $\begin{array}{l}\text { Amount paid for } \\
\text { antenatal care services }\end{array}$ & $\begin{array}{l}\text { Continuous (ranges from KSh. } \\
0 \text { to KSh. 20,000) }\end{array}$ \\
\hline $\begin{array}{l}\text { Amount paid for } \\
\text { delivery services }\end{array}$ & $\begin{array}{l}\text { Continuous (ranges from KSh. } \\
0 \text { to KSh. 32,000) }\end{array}$ \\
\hline $\begin{array}{l}\text { Amount paid for } \\
\text { postnatal care services }\end{array}$ & $\begin{array}{l}\text { Continuous (ranges from KSh. } \\
0 \text { to KSh. 20,000) }\end{array}$ \\
\hline \multicolumn{2}{|l|}{ Covariates } \\
\hline \multirow[t]{2}{*}{ Study site } & $0=$ Non-voucher sites \\
\hline & $1=$ Voucher sites \\
\hline \multirow[t]{2}{*}{ Study round } & $0=2010-2011$ survey \\
\hline & $1=2012$ survey \\
\hline Study round $\times$ Study site & $\begin{array}{l}\text { Interaction term between } \\
\text { study round and study site }\end{array}$ \\
\hline $\begin{array}{l}\text { Maternal age at } \\
\text { birth of child }\end{array}$ & $\begin{array}{l}\text { Single years (ranges from } 14 \text { to 48); } \\
\text { included in models for safe } \\
\text { motherhood services }\end{array}$ \\
\hline Current age of respondent & $\begin{array}{l}\text { Single years (ranges from } 15 \text { to } 49 \text { ); } \\
\text { included in models for family } \\
\text { planning services }\end{array}$ \\
\hline \multirow[t]{2}{*}{ Education level } & $0=$ No schooling/pre-unit/primary \\
\hline & $1=$ Secondary and above \\
\hline \multirow[t]{2}{*}{ Current marital status } & $0=$ Never $/$ formerly married \\
\hline & $1=$ Married/living together \\
\hline \multirow[t]{2}{*}{ Type of place of residence } & $0=$ Urban \\
\hline & $1=$ Rural \\
\hline \multirow[t]{2}{*}{ Duration of residence } & $0=$ Less than 5 years/visitor \\
\hline & $1=5$ years or more/always \\
\hline \multirow[t]{2}{*}{ Religious affiliation } & $0=$ Catholic/Muslim/other \\
\hline & 1 = Protestant/other Christian \\
\hline \multirow[t]{2}{*}{ Poverty status $^{a}$} & $0=$ Non-poor (17-24 points) \\
\hline & $1=$ Poor (8-16 points) \\
\hline Parity & Ranges from 1 to 16 \\
\hline \multirow[t]{2}{*}{ Place service sought } & $0=$ Private health facility \\
\hline & $1=$ Public health facility \\
\hline
\end{tabular}

${ }^{a}$ Based on the poverty grading tool used by the voucher management agency to identify beneficiaries; KSh: Kenya Shilling the proportions that had ever used the long-term methods that are subsidized by the voucher program (implants, IUCD and bilateral tubal ligation). In addition, a significantly greater proportion of women in non-voucher compared to voucher sites used the long-term methods in the 12 months preceding the 2010-2011 survey. By 2012, the proportions of women from voucher and non-voucher sites that used the methods in the 12 months preceding the survey were similar. In both surveys, most of the women in voucher and non-voucher sites who used a method in the past 12 months obtained it from a public health facility with no significant variations by study site (Table 4).

As expected, none of the women in non-voucher sites had ever used any of the reproductive health vouchers in either 2010-2011 or 2012. By contrast, the proportion of women in voucher sites that had used the safe motherhood voucher increased from $15 \%$ in the 2010-2011 survey to $44 \%$ in the 2012 survey. Similarly, the proportion that had ever used the family planning voucher increased from $2 \%$ in 2010-2011 to $7 \%$ in 2012. In both surveys, none of the women from voucher sites reported having ever used the gender-based violence recovery services voucher. It could be that women felt stigmatized if they reported using the gender-based violence recovery services voucher which may have contributed to underreporting or lack of awareness about the voucher given that it was only available at the facility level.

Results in Table 4 further show that nearly all women who had a birth in the two years preceding the survey sought antenatal care with no significant variations by study site. There were no significant variations in the source of antenatal, delivery and postnatal care services for women from voucher and non-voucher sites in 2010-2011. In 2012, however, the proportions of women that obtained antenatal, delivery and postnatal care services from private health facilities were significantly higher among those from voucher compared to those from non-voucher sites. The proportions of women that obtained antenatal and postnatal care services from public health facilities were, on the other hand, significantly higher in non-voucher than in voucher sites. For delivery care, there was no significant difference in the proportions of women from voucher and non-voucher sites that obtained the services from public health facilities (Table 4).

\section{Changes in payment patterns for services}

Overall, there was a greater reduction in the proportions that paid for family planning, antenatal, delivery and postnatal care services in voucher than in non-voucher sites (Table 5). In absolute terms, the differences in changes between voucher and non-voucher sites were greater for safe motherhood than for family planning services. With respect to amounts paid, there was no change in the 
Table 3 Percent distribution of women by background characteristics, survey year and study site

\begin{tabular}{|c|c|c|c|c|c|c|}
\hline \multirow[t]{2}{*}{ Characteristics } & \multicolumn{3}{|l|}{ 2010-2011 survey } & \multicolumn{3}{|l|}{2012 survey } \\
\hline & Voucher sites (\%) & Non-voucher sites (\%) & $P$-value & Voucher sites (\%) & Non-voucher sites (\%) & $P$-value \\
\hline Current age (years) & & & $p<0.01$ & & & $p<0.01$ \\
\hline $15-24$ & 34.4 & 28.4 & & 37.7 & 27.7 & \\
\hline $25-34$ & 44.8 & 45.8 & & 43.9 & 47.7 & \\
\hline 35 and above & 20.4 & 25.9 & & 18.0 & 24.6 & \\
\hline Don't know & 0.3 & 0.0 & & 0.4 & 0.0 & \\
\hline Highest education level & & & $p<0.01$ & & & $p<0.01$ \\
\hline No schooling/pre-unit & 10.2 & 3.1 & & 9.8 & 1.9 & \\
\hline Primary & 67.3 & 67.9 & & 67.0 & 65.4 & \\
\hline Secondary and above & 22.5 & 29.0 & & 23.2 & 32.7 & \\
\hline Current marital status & & & $p=0.16$ & & & $p=0.09$ \\
\hline Never/formerly married & 10.6 & 10.3 & & 13.8 & 11.3 & \\
\hline Married/living together & 80.3 & 82.5 & & 78.6 & 81.5 & \\
\hline Formerly married & 9.1 & 7.1 & & 7.6 & 7.2 & \\
\hline Place of residence & & & $p<0.01$ & & & $p<0.01$ \\
\hline Urban & 19.4 & 13.0 & & 17.5 & 12.7 & \\
\hline Rural & 80.7 & 87.0 & & 82.5 & 87.3 & \\
\hline Duration of residence & & & $p<0.05$ & & & $p=0.20$ \\
\hline Less than 5 years/visitor & 34.7 & 39.1 & & 34.9 & 37.2 & \\
\hline 5 years or more/always & 65.3 & 60.9 & & 65.1 & 62.8 & \\
\hline Religious affiliation & & & $p<0.01$ & & & $p<0.01$ \\
\hline Catholic & 24.7 & 28.6 & & 24.9 & 27.1 & \\
\hline Protestant/other Christian & 61.7 & 70.3 & & 62.9 & 70.2 & \\
\hline Muslim & 6.9 & 0.3 & & 5.4 & 0.7 & \\
\hline Traditional/no religion & 6.8 & 0.8 & & 6.8 & 1.9 & \\
\hline Poverty status & & & $p<0.01$ & & & $p<0.01$ \\
\hline Non-poor (17-24 points) & 18.7 & 29.1 & & 23.3 & 33.0 & \\
\hline Poor (8-16 points) & 81.3 & 71.0 & & 76.7 & 67.0 & \\
\hline Parity & & & $p=0.69$ & & & $p=0.42$ \\
\hline 0 & 4.1 & 3.1 & & 5.5 & 4.4 & \\
\hline $1-2$ & 40.2 & 41.0 & & 39.6 & 41.0 & \\
\hline $3-4$ & 31.9 & 31.6 & & 32.4 & 32.5 & \\
\hline 5 and above & 23.3 & 23.9 & & 22.5 & 22.1 & \\
\hline Missing & 0.5 & 0.5 & & 0.0 & 0.1 & \\
\hline Number of women & 1,742 & 1,191 & & 1,808 & 1,286 & \\
\hline
\end{tabular}

Percentages may not sum to exactly 100 in some cases due to rounding; $p$-values are from Chi-square tests for differences between sites

average and median amount that women paid for family planning services in voucher sites over time. In nonvoucher sites, the average amount paid for family planning services increased by KSh. 32 (representing a $52 \%$ increase) while the median amount remained unchanged at KSh. 50. The average amount paid for antenatal care services declined by KSh. 27 (20\% decline) in voucher sites while the median amount declined from KSh. 50 in 20102011 to zero in 2012 (100\% decline). By contrast, the average amount paid for antenatal care in non-voucher sites increased by KSh. 139 while the median amount increased by KSh. 50 over time (representing $78 \%$ and $40 \%$ increase respectively).

The decline in the average amount paid for delivery and postnatal care services was more than twice greater in voucher than in non-voucher sites (Table 5). In particular, the average amount paid for delivery services declined by KSh. 1,067 and KSh. 497 in voucher and non-voucher 
Table 4 Percent distribution of women by use of reproductive health services, survey year and study site

\begin{tabular}{|c|c|c|c|c|}
\hline \multirow[t]{2}{*}{ Services } & \multicolumn{2}{|l|}{ 2010-2011 survey } & \multicolumn{2}{|l|}{2012 survey } \\
\hline & Voucher sites (\%) & Non-voucher sites (\%) & Voucher sites (\%) & Non-voucher sites (\%) \\
\hline Ever used family planning & $(N=1,742)$ & $(N=1,191)$ & $(N=1,808)$ & $(N=1,286)$ \\
\hline Used any method & 59.6 & $75.2^{* *}$ & 66.9 & $75.0^{* *}$ \\
\hline Used long-term method ${ }^{\mathrm{a}}$ & 7.6 & 9.6 & 13.8 & 13.6 \\
\hline Used FP last 12 months & $(N=1,742)$ & $(N=1,191)$ & $(N=1,808)$ & $(N=1,286)$ \\
\hline Used any method & 39.2 & $54.5^{* *}$ & 47.9 & $52.6^{* *}$ \\
\hline Used long-term method ${ }^{a}$ & 5.3 & $7.1^{*}$ & 10.1 & 10.3 \\
\hline Source of last FP method ${ }^{\mathrm{b}}$ & $(N=683)$ & $(N=649)$ & $(N=866)$ & $(N=676)$ \\
\hline Public health facility & 79.7 & 76.9 & 13.4 & 16.0 \\
\hline Private health facility & 14.4 & 15.6 & 71.4 & 70.7 \\
\hline Other/missing & 6.0 & 7.6 & 15.2 & 13.3 \\
\hline Ever use of voucher & $(N=1,742)$ & $(N=1,191)$ & $(N=1,808)$ & $(N=1,286)$ \\
\hline Used safe motherhood & 15.4 & $0.0^{* *}$ & 43.9 & $0.0^{* *}$ \\
\hline Used family planning & 1.8 & $0.0^{* *}$ & 6.6 & $0.0^{* *}$ \\
\hline Used gender-based violence & 0.0 & 0.0 & 0.0 & 0.0 \\
\hline Used any voucher & 16.0 & $0.0^{* *}$ & 45.0 & $0.0^{* *}$ \\
\hline Sought antenatal care for most recent birth & $100.0(N=588)$ & $100.0(N=361)$ & $96.6(N=912)$ & $96.5(N=632)$ \\
\hline Source of antenatal care & $(N=588)$ & $(N=361)$ & $(N=881)$ & $(N=610)$ \\
\hline Public health facility & 85.0 & 87.5 & 78.9 & $89.0^{* *}$ \\
\hline Private health facility & 14.0 & 11.9 & 20.7 & $11.0^{* *}$ \\
\hline Home/other/missing & 1.0 & 0.6 & 0.5 & 0.0 \\
\hline Source of delivery care & $(N=588)$ & $(N=361)$ & $(N=912)$ & $(N=632)$ \\
\hline Public health facility & 39.0 & 41.0 & 42.3 & 43.5 \\
\hline Private health facility & 14.1 & 12.7 & 21.9 & $13.0^{* *}$ \\
\hline Home/other/missing & 46.9 & 46.2 & 35.8 & $43.5^{* *}$ \\
\hline Source of postnatal care & $(N=588)$ & $(N=361)$ & $(N=912)$ & $(N=632)$ \\
\hline Public health facility & 42.4 & 43.2 & 60.2 & $68.2^{* *}$ \\
\hline Private health facility & 13.8 & 11.6 & 22.5 & $13.9^{* *}$ \\
\hline Home/other/missing & 43.9 & 45.2 & 17.3 & 17.9 \\
\hline
\end{tabular}

${ }^{a}$ Include methods that are subsidized by the voucher program (implants, intrauterine contraceptive device and female sterilization); ${ }^{\mathrm{b}}$ Among those who used a method in the last 12 months; FP: Family planning; ${ }^{*} p<0.05 ;{ }^{* *} p<0.01$

sites respectively (representing $52 \%$ and $16 \%$ decline respectively). Similarly, the average amount paid for postnatal care services declined by KSh. 156 and KSh. 73 in voucher and non-voucher sites respectively (90\% and $40 \%$ decline respectively). The median amount paid for delivery services declined from KSh. 500 to zero (100\% decline) in voucher sites and by $25 \%$ in non-voucher sites (from KSh. 2,000 to KSh. 1,500). By contrast, the median amount paid for postnatal care services remained unchanged at zero in both voucher and non-voucher sites.

\section{Difference-in-differences estimates}

The results from the multivariate linear regression models with the difference-in-differences estimates for the proportions paying for various reproductive health services at facilities in voucher and non-voucher sites over time are presented in Table 6. The difference-indifferences estimates were statistically significant for the proportions paying for antenatal $(p<0.01)$, delivery $(p<0.01)$ and postnatal care $(p<0.05)$ but not for family planning services $(p=0.75)$. The results further show that the proportions that paid for family planning services significantly declined with higher parity $(p<0.05)$. In addition, the proportions that paid for antenatal and delivery care services were significantly greater among those who sought services from public than from private health facilities $(p<0.05$ and $p<0.01$ respectively). There was, however, no significant difference in the proportions paying for the various reproductive health services by poverty status (Table 6). 
Table $\mathbf{5}$ Changes in payment patterns for reproductive health services at facilities by study site and survey year

\begin{tabular}{|c|c|c|c|c|c|c|}
\hline \multirow[t]{2}{*}{ Indicator } & \multicolumn{3}{|l|}{ Voucher sites } & \multicolumn{3}{|l|}{ Non-voucher sites } \\
\hline & 2010-2011 survey & 2012 survey & Change & 2010-2011 survey & 2012 survey & Change \\
\hline \multicolumn{7}{|c|}{ Proportions paying (\%) } \\
\hline Family planning & $73.8(N=598)$ & $71.9(N=750)$ & -1.9 & $86.3(N=546)$ & $85.2(N=568)$ & -1.1 \\
\hline Antenatal care & $69.1(N=433)$ & $42.0(N=877)$ & -27.1 & $85.0(N=267)$ & $85.6(N=610)$ & 0.6 \\
\hline Delivery care & $66.1(N=221)$ & $30.6(N=586)$ & -35.5 & $92.1(N=140)$ & $89.6(N=357)$ & -2.5 \\
\hline Postnatal care & $27.8(N=209)$ & $7.3(N=754)$ & -20.5 & $26.1(N=138)$ & $18.1(N=519)$ & -8.0 \\
\hline \multicolumn{7}{|c|}{ Mean amount paid (KSh) } \\
\hline Family planning & $50.00(N=598)$ & $50.00(N=750)$ & 0.00 & $61.00(N=546)$ & $93.00(N=568)$ & 32.00 \\
\hline Antenatal care & $136.00(N=429)$ & $109.00(N=876)$ & -27.00 & $178(N=266)$ & $317.00(N=606)$ & 139.00 \\
\hline Delivery care & $2,047.00(N=215)$ & $980.00(N=581)$ & $-1,067.00$ & $3,193.00(N=133)$ & $2,696.00(N=352)$ & -497.00 \\
\hline Postnatal care & $174.00(N=204)$ & $18.00(N=754)$ & -156.00 & $151.00(N=137)$ & $78.00(N=518)$ & -73.00 \\
\hline \multicolumn{7}{|c|}{ Median amount paid (KSh) } \\
\hline Family planning & $30.00(N=598)$ & $30.00(N=750)$ & 0 & $50.00(N=546)$ & $50.00(N=568)$ & 0.00 \\
\hline Antenatal care & $50.00(N=429)$ & $0.00(N=876)$ & -50.00 & $125.00(N=266)$ & $175.00(N=606)$ & 50.00 \\
\hline Delivery care & $500.00(N=215)$ & $0.00(N=581)$ & -500.00 & $2,000.00(N=133)$ & $1,500.00(N=352)$ & -500.00 \\
\hline Postnatal care & $0.00(N=204)$ & $0.00(N=754)$ & 0.00 & $0.00(N=137)$ & $0.00(N=518)$ & 0.00 \\
\hline
\end{tabular}

Non-zero positive values indicate an increase in the estimates over time; KSh: Kenya Shilling (1 USD $\approx$ KSh. 86)

Table 7 presents the results from the multivariate linear regression models with the difference-in-differences estimates for the amount paid for reproductive health services at facilities in voucher and non-voucher sites over time. The estimates for the differences in changes in the amount paid for services were statistically significant for family planning and antenatal care $(p<0.01$ in each case) but not for delivery $(p=0.11)$ and postnatal care services $(p=0.45)$. Other results show that the amount paid for antenatal and delivery care services significantly declined with parity ( $p<0.01$ in each case). In addition, the amount paid for family planning, antenatal and delivery care services was significantly lower among women who sought services from public than from private health facilities (Table 7). Women with at least secondary level education significantly paid more for family planning and delivery care than those with lower levels of education while poor women significantly paid less for delivery and postnatal care services compared to their non-poor counterparts.

\section{Discussion}

The major finding of this paper is that over time, there were significantly greater declines in the proportions of women from voucher sites that paid for antenatal, delivery and postnatal care services at health facilities compared to those from non-voucher sites. The changes were also consistent with increased uptake of the safe motherhood voucher over time in voucher sites, which nearly tripled between 2010-2011 and 2012. There was, however, no significant difference in changes in the proportions of women from voucher and non-voucher sites that paid for family planning services. Although the proportion of women in voucher sites that had ever used the family planning voucher more than tripled between the two surveys, the uptake of the voucher was substantially lower compared to the safe motherhood voucher. The findings therefore indicate that the reproductive health vouchers program significantly reduced the proportions of women in the community that paid out of pocket for safe motherhood services. The findings further suggest that significant reductions in the proportions of women in the community paying for reproductive health services can be achieved through strategies aimed at increasing the uptake of the vouchers. Such strategies include intensive marketing campaigns, proper targeting of clients, controlling potential fraud, widening the range of services that are subsidized, increasing the number of accredited facilities to ensure ease of access to services, and effectively monitoring and improving quality of care through practice [10, 27].

The second major finding of the paper is that there were significant differences in changes in the amount paid for family planning and antenatal care services by women from voucher sites compared to those from nonvoucher sites. The average amount paid for family planning services by women from voucher sites remained unchanged while the average amount paid for antenatal care declined over time. By contrast, the average amount paid for the two services by women from non-voucher sites increased over time. The significance of the differencein-differences estimates for these outcomes could therefore 
Table 6 Coefficient estimates from multivariate regression models for proportions of women paying for reproductive health services at health facilities

\begin{tabular}{|c|c|c|c|c|}
\hline Covariates & Family planning & Antenatal care & Delivery care & Postnatal care \\
\hline Study site (voucher sites $=1$ ) & $-0.12^{* *}(-0.18 ;-0.06)$ & $0.16^{* *}(-0.25 ;-0.06)$ & $-0.27^{* *}(-0.37 ;-0.17)$ & $-0.00(-0.11 ; 0.11)$ \\
\hline Study round (2012 survey $=1$ ) & $-0.01(-0.06 ; 0.04)$ & $0.01(-0.05 ; 0.06)$ & $-0.04(-0.10 ; 0.02)$ & $-0.09^{*}(-0.17 ;-0.01)$ \\
\hline Study round $\times$ Study site & $-0.01(-0.08 ; 0.06)$ & $-0.27^{* *}(-0.36 ;-0.18)$ & $-0.30^{* *}(-0.40 ; 0.19)$ & $-0.12^{*}(-0.22 ;-0.02)$ \\
\hline Current age (single years) & $0.00(-0.00 ; 0.01)$ & $\mathrm{n} / \mathrm{a}$ & $\mathrm{n} / \mathrm{a}$ & $\mathrm{n} / \mathrm{a}$ \\
\hline Maternal age at last birth (single years) & $\mathrm{n} / \mathrm{a}$ & $0.00(-0.01 ; 0.01)$ & $0.00(-0.00 ; 0.01)$ & $-0.00(-0.01 ; 0.00)$ \\
\hline Highest education level (secondary and above $=1$ ) & $-0.02(-0.06 ; 0.02)$ & $0.01(-0.04 ; 0.06)$ & $0.12(-0.03 ; 0.01)$ & $-0.04(-0.09 ; 0.00)$ \\
\hline Current marital status (married/ living together $=1$ ) & $0.05^{*}(0.00 ; 0.11)$ & $0.04(-0.01 ; 0.09)$ & $0.02(-0.04 ; 0.08)$ & $-0.04(-0.09 ; 0.02)$ \\
\hline Type of place of residence (rural $=1$ ) & $0.02(-0.07 ; 0.12)$ & $-0.07(-0.18 ; 0.03)$ & $-0.06(-0.19 ; 0.07)$ & $-0.06(-0.13 ; 0.02)$ \\
\hline Duration of residence $(5$ or more years/always $=1$ ) & $-0.02(-0.06 ; 0.02)$ & $-0.02(-0.06 ; 0.02)$ & $-0.02(-0.07 ; 0.03)$ & $0.01(-0.03 ; 0.05)$ \\
\hline Religious affiliation (Protestant/ other Christian =1) & $0.02(-0.02 ; 0.06)$ & $0.01(-0.03 ; 0.05)$ & $0.01(-0.04 ; 0.06)$ & $0.01(-0.03 ; 0.05)$ \\
\hline Poverty status (poor $=1$ ) & $-0.01(-0.05 ; 0.03)$ & $-0.00(-0.04 ; 0.04)$ & $0.01(-0.04 ; 0.06)$ & $0.02(-0.06 ; 0.02)$ \\
\hline Parity & $-0.02^{* *}(-0.04 ;-0.01)$ & $0.00(-0.01 ; 0.02)$ & $-0.02(-0.04 ; 0.00)$ & $0.01(-0.00 ; 0.02)$ \\
\hline Facility type (public $=1)$ & $-0.05^{*}(-0.10 ;-0.00)$ & $0.10^{*}(0.02 ; 0.18)$ & $0.21^{* *}(0.15 ; 0.28)$ & $-0.01(-0.06 ; 0.04)$ \\
\hline Constant & $0.90^{* *}(0.76 ; 1.05)$ & $0.78^{* *}(0.61 ; 0.95)$ & $0.75^{* *}(0.54 ; 0.95)$ & $0.41^{* *}(0.23 ; 0.58)$ \\
\hline Number of cases & 2,461 & 2,179 & 1,302 & 1,618 \\
\hline
\end{tabular}

Estimates are based on Equation (1) in the text; $\mathrm{n} / \mathrm{a}$ : not applicable; $95 \%$ confidence intervals are in parentheses; ${ }^{*} p<0.05 ;{ }^{* *} p<0.01$

be due to the variations in trends in the average amount paid for the services. Although there were greater declines in the average amount paid for delivery and postnatal care services by women from voucher sites compared to those from non-voucher sites, the difference-in-differences estimates were not statistically significant. Ideally, voucher clients should not pay anything for services that are subsidized by the program. This was corroborated by the data which showed that the median amount paid for the services by women who had ever used the vouchers was zero and

Table 7 Coefficient estimates from multivariate regression models for amount paid for reproductive health services at health facilities

\begin{tabular}{|c|c|c|c|c|}
\hline Covariates & Family planning & Antenatal care & Delivery care & Postnatal care \\
\hline Study site (voucher sites $=1$ ) & $-7.23(-19.82 ; 5.23)$ & $-41.16(-85.39 ; 3.06)$ & $-844.79(-1701.30 ; 11.71)$ & $70.39(-207.79 ; 348.57)$ \\
\hline Study round (2012 survey $=1$ ) & $32.63^{* *}(13.90 ; 51.37)$ & $140.47^{* *}(65.13 ; 215.80)$ & $-335.19(-1119.16 ; 448.79)$ & $-41.61(-224.02 ; 140.80)$ \\
\hline Study round $\times$ Study site & $-33.43^{* *}(-54.97 ; 11.88)$ & $-172.05^{* *}(-252.65 ;-91.45)$ & $-726.53(-1624.88 ; 171.83)$ & $-103.93(-376.60 ; 168.74)$ \\
\hline Current age (single years) & $1.10(-0.27 ; 2.28)$ & $\mathrm{n} / \mathrm{a}$ & $\mathrm{n} / \mathrm{a}$ & $n / a$ \\
\hline $\begin{array}{l}\text { Maternal age at last birth (single } \\
\text { years) }\end{array}$ & $\mathrm{n} / \mathrm{a}$ & $2.79(-0.21 ; 6.15)$ & $111.02^{* *}(52.26 ; 169.79)$ & $9.30(-13.05 ; 31.66)$ \\
\hline $\begin{array}{l}\text { Highest education level } \\
\text { (secondary and above }=1 \text { ) }\end{array}$ & $22.11^{* *}(5.74 ; 38.48)$ & $7.28(-42.27 ; 56.84)$ & $600.90^{*}(126.53 ; 1075.27)$ & $58.32(17.99 ; 134.64)$ \\
\hline $\begin{array}{l}\text { Current marital status } \\
\text { (married/ living together }=1 \text { ) }\end{array}$ & $3.27(-8.06 ; 14.59)$ & $47.82(-5.83 ; 101.47)$ & $169.07(-354.16 ; 692.31)$ & $-69.51(-212.27 ; 73.25)$ \\
\hline Type of place of residence (rural $=1$ ) & $8.21(-0.84 ; 17.26)$ & $-55.54(-124.28 ; 13.19)$ & $-303.86(-978.63 ; 370.92)$ & $37.37(-48.88 ; 123.62)$ \\
\hline $\begin{array}{l}\text { Duration of residence } \\
(5 \text { or } \text { more years/always }=1)\end{array}$ & $0.47(-9.78 ; 10.72)$ & $60.40(-10.27 ; 131.08)$ & $-160.04(-597.01 ; 276.93)$ & $7.60(-51.26 ; 66.46)$ \\
\hline $\begin{array}{l}\text { Religious affiliation (Protestant/ } \\
\text { other Christian }=1 \text { ) }\end{array}$ & $-0.96(-14.89 ; 12.97)$ & $5.48(-39.61 ; 50.56)$ & $13.60(-343.87 ; 371.08)$ & $50.15^{*}(4.74 ; 95.56)$ \\
\hline Poverty status $($ poor $=1$ ) & $2.12(-10.10 ; 14.34)$ & $-31.70(-79.88 ; 16.49)$ & $-455.64^{*}(-888.01 ;-23.27)$ & $-112.22^{*}(-212.86 ;-11.57)$ \\
\hline Parity & $-0.17(-5.50 ; 5.17)$ & $-24.52^{* *}(-40.12 ;-8.93)$ & $-325.94^{* *}(-485.99 ;-165.89)$ & $-26.59(-82.13 ; 28.94)$ \\
\hline Facility type (public $=1$ ) & $-43.74^{* *}(-63.88 ;-23.59)$ & $-90.07^{* *}(-148.14 ;-32.00)$ & $-638.31^{*}(-1238.26 ;-38.35)$ & $-11.23(-101.89 ; 79.43)$ \\
\hline Constant & $50.44^{* *}(22.17 ; 78.70)$ & $244.07^{* *}(131.94 ; 356.20)$ & $1715.90^{*}(61.13 ; 3370.68)$ & $3.19(-379.66 ; 386.05)$ \\
\hline Number of cases & 2,461 & 2,169 & 1,279 & 1,611 \\
\hline
\end{tabular}

Estimates are based on Equation (1) in the text; $n / a$ : not applicable; $95 \%$ confidence intervals are in parentheses; ${ }^{*} p<0.05 ;{ }^{* *} p<0.01$ 
that none of the women who had ever used the voucher paid for services when they used it (not shown). It could therefore be that in both surveys, women from voucher sites who paid for delivery and postnatal care services were largely non-beneficiaries of the program.

The findings of the paper are consistent with the view in the literature that demand-side subsidies combined with supply-side incentives have the potential to protect economically disadvantaged individuals from financial catastrophe and impoverishment arising from out-ofpocket expenditures on health care services [5, 10-13]. However, substantial reductions in out-of-pocket expenditure for voucher beneficiaries can be achieved if the programs subsidize both transport and service costs as is the case with the Bangladesh maternal health voucher scheme $[28,29]$. Findings from the Kenya voucher program, for instance, show that some women who purchased the vouchers failed to use them because transportation costs to accredited health facilities were higher than service costs at nearby non-contracted providers $[27,30]$.

The other strategies that governments in developing countries have adopted to cushion poor households from catastrophic out-of-pocket expenditure on health services are abolition of user fees and conditional cash transfers. For instance, the Kenya Government abolished user fees for safe motherhood services at public health facilities from June 2013 [31]. However, available evidence suggests that although removal of user fees increases service uptake, it may have a negative impact on the quality of care [32]. In addition, the effectiveness of conditional cash transfer programs in settings such as that of subSaharan Africa may be affected by supply side barriers [33]. Unlike abolition of user fees and conditional cash transfers, vouchers aim to improve service delivery through explicit performance-based contracting with service providers based on set minimum standards of care as well as through stimulating competition for voucher clients $[10,15]$. In addition, vouchers not only empower clients to seek services but also generate revenue for health facilities which can be used to improve service quality.

The above findings might, however, be influenced by the study's limitations. First, there was no random assignment of facilities, villages or clients to the voucher program. It could therefore be argued that any differences between voucher and non-voucher sites could be due to unobserved differences in respondent characteristics. Second, the identification of respondents from within specific geographical distances to contracted facilities might lead to under- or over-representation of voucher users depending on how spread they are from the facilities. This could, in turn, result in under- or over-estimation of the community-level effect of the program on outof-pocket expenditure on reproductive health services at facilities. Under-estimation may result from underrepresentation of voucher clients while over-estimation may arise if voucher clients were over-represented in the sampled areas. Third, the effect of the program could be undermined by periods of low voucher sales especially between November 2008 and May 2009 which were due to delays in finalization of contracts and printing of vouchers as the program transitioned from pilot to scale-up phase [34]. The low sales might have affected the number of beneficiaries, hence limiting the impact of the program at the community level.

\section{Conclusion}

Despite the limitations, the findings of this paper suggest that the reproductive health vouchers program in Kenya significantly contributed to reductions in the proportions of women in the community that paid out-of-pocket for safe motherhood services in the regions where it was implemented.

\section{Abbreviations}

GDP: Gross domestic product; GPS: Global positioning system; IUCD: Intra-uterine contraceptive device; KEMRI: Kenya Medical Research Institute; KfW: Kreditanstaldt fuer Wiederaufbau (German Development Bank); KSh: Kenya Shilling; NCST: National Council for Science and Technology; NCPD: National Council for Population and Development; OBA: Output-based aid; RH: Reproductive health; WHO: World Health Organization.

\section{Competing interests}

The authors declare that they have no competing interests.

\section{Authors' contributions}

FO conducted the analysis, interpretation of results, and drafting of the manuscript. CW and BB were involved in the conceptual design of the study and in reviewing the manuscript for substantial intellectual content. LK and TA contributed to the interpretation of the data and revising the manuscript for substantial intellectual content. All authors read and approved the final manuscript.

\section{Acknowledgements}

The reproductive health vouchers program is implemented by the Government of Kenya with major funding from the German Development Bank (KfW). The evaluation project was funded by the Bill and Melinda Gates Foundation and was implemented by the Population Council in collaboration with the National Council for Population and Development (NCPD), the Ministry of Health, and PricewaterhouseCoopers. The project obtained ethical and research clearance from the Institutional Review Board of the Population Council, the Ethics Review Committee of the Kenya Medical Research Institute (KEMRI), the National Council for Science and Technology (NCST), and the Ministry of Health. The opinions expressed in the paper are, however, solely those of the authors and do not necessarily reflect the views of the funding or implementing agencies.

\section{Author details}

${ }^{1}$ Reproductive Health Program, Population Council, Ralph Bunche Road, General Accident House, P.O. Box 17643, Nairobi 00500, Kenya. ${ }^{2}$ Reproductive Health Program, Population Council, 4301 Connecticut Avenue, Washington, DC, NW 20008, USA. ${ }^{3}$ Brunel University London, Kingston Lane, Uxbridge UB83PH, London.

Received: 21 July 2014 Accepted: 11 August 2015

Published online: 25 August 2015 


\section{References}

1. Chuma J, Maina T. Catastrophic healthcare spending and impoverishment in Kenya. BMC Health Serv Res. 2012;12:413.

2. Van Damme W, Van Leemput L, Por I, Hardeman W, Meessen B. Out-of-pocket health expenditure and debt in poor households: Evidence from Cambodia. Trop Med Int Health. 2004;9:273-80.

3. Whitehead M, Dahlgren G, Evans T. Equity and health sector reforms: Can lowincome countries escape the medical poverty gap? Lancet. 2001;358:833-6.

4. Xu K, Evans DB, Kawabata K, Zeramdini R, Klavus J, Murray CJL. Household catastrophic health expenditure: A multicountry analysis. Lancet. 2003:362:111-7.

5. Xu K, Evans B, Carrin G, Aguilar-Rivera AM, Musgrove P, Evans T. Protecting households from catastrophic health spending. Health Aff. 2007;26:972-83.

6. Leive A, Xu K. Coping with out-of-pocket health payments: Empirical evidence from 15 African countries. Bull World Health Org. 2008:86:849-56.

7. Su TT, Kouyaté B, Flessa S. Catastrophic household expenditure for health care in a low-income society: A study from Nouna District, Burkina Faso. Bull World Health Org. 2006:84:21-7.

8. World Bank. A guide to competitive vouchers in health. Washington, DC: The World Bank; 2005.

9. World Health Organization (WHO). Designing health financing systems to reduce catastrophic health expenditure. Technical Briefs for Policy Makers No. 2. Geneva: WHO; 2005.

10. Bhatia MR, Gorter AC. Improving access to reproductive and child health services in developing countries: Are competitive voucher schemes an option? J Int Dev. 2007:19:975-81.

11. Jacobs B, Price N. Improving access for the poorest to public sector health services: Insights from Kirivong Operational Health District in Cambodia. Health Pol Plan. 2006;21:27-39.

12. Peters DH, Garg A, Bloom G, Walker DG, Brieger WR, Rahman MH. Poverty and access to health care in developing countries. Annals New York Academy Sci. 2008;1136:161-71.

13. Ranson MK. Reduction of catastrophic health care expenditures by a community-based health insurance scheme in Gujarat, India: Current experiences and challenges. Bull World Health Org. 2002:80:613-21.

14. Cave M. Voucher programmes and their role in distributing public services. Org Econ Coop Dev J Budg. 2001;1:59-88.

15. Gorter A, Sandiford P, Rojas Z, Salvetto M. Competitive voucher schemes for health: Background paper. ICAS: Mexico; 2003.

16. Janisch CP, Potts M. Smart aid- the role of output-based assistance. Lancet. 2005;366:1343-4.

17. Feikin DR, Nguyen LM, Adazu K, Ombok M, Audi A, Slutsker L, et al. The impact of distance of residence from a peripheral health facility on pediatric health utilization in Western Kenya. Trop Med Int Health. 2009;14:54-61.

18. Schoeps A, Gabrysch S, Niamba L, Sie' A, Becher H. The effect of distance to health-care facilities on childhood mortality in rural Burkina Faso. Amer J Epid. 2011;173:492-8.

19. Kyomuhendo GB. Low use of maternity services in Uganda: Impact of women's status, traditional beliefs and limited resources. Reprod Health Matters. 2003:11:16-26.

20. Stekelenburg J, Kyanamina S, Mukelabai M, Wolffers I, van Roosmalen J. Waiting too long: Low use of maternal health services in Kalabo, Zambia. Trop Med Int Health. 2004;9:390-8.

21. Hagenmeyer EG, Griffin D, Ahmed R, Teshome E, Barsch A, Muga R, et al. Design study for output-based assistance programme Kenya: Final report. Berlin: IGES Paper 05-67; 2005.

22. PricewaterhouseCoopers. Reproductive Health Output-Based Aid: End of Pilot Project Report. Vol. 1. Nairobi: PricewaterhouseCoopers; 2008

23. RH-OBA Technical Committee. RH-OBA Review on Quality Assurance: Final Report. Nairobi: RH-OBA Technical Committee; 2009.

24. Janisch CP, Albrecht M, Wolfschuetz A, Kundu F, Klein S. Vouchers for health: A demand side output-based aid approach to reproductive health services in Kenya. Global Pub Health. 2010:5:578-94.

25. Warren C, Abuya T, Obare F, Sunday J, Njuki R, Askew I, et al. Evaluation of the impact of the voucher and accreditation approach on improving reproductive health behaviors and status in Kenya. BMC Pub Health. 2011;11:177.

26. Gertler PJ, Martinez S, Premand P, Rawlings LB, Vermeersch CMJ. Impact Evaluation in Practice. Washington, DC: The World Bank; 2011. p. 95-105.

27. Abuya T, Njuki R, Warren CE, Okal J, Obare F, Kanya L, et al. A policy analysis of the implementation of a reproductive health vouchers program in Kenya. BMC Pub Health. 2012;12:540.
28. Ahmed S, Khan MM. A maternal health voucher scheme: What have we learned from the demand-side financing scheme in Bangladesh? Health Pol Plan. 2011;26:25-32.

29. Hatt L, Nguyen H, Sloan N, Miner S, Magvanjav O, Sharma A, et al. Economic Evaluation of Demand-Side Financing (DSF) for Maternal Health in Bangladesh. Bethesda, MD: Review, Analysis and Assessment of Issues Related to Health Care Financing and Health Economics in Bangladesh, Abt Associates Inc.; 2011.

30. Njuki R, Okal J, Warren CE, Obare F, Abuya T, Kanya L, et al. Exploring the effectiveness of the output-based aid voucher program to increase uptake of gender-based violence recovery services in Kenya: A qualitative evaluation. BMC Pub Health. 2012;12:426.

31. Ministry of Health [Kenya]. Free Maternity Services. Government Circular ACC/FM HS/1/28A of April 2014. Nairobi: Ministry of Health; 2014.

32. Lagarde $M$, Palmer $N$. The impact of user fees on health service utilization in low- and middle-income countries: How strong is the evidence? Bull World Health Org. 2008:86:839-48.

33. Lagarde $\mathrm{M}$, Haines $\mathrm{A}$, Palmer $\mathrm{N}$. The impact of conditional cash transfers on health outcomes and use of health services in low and middle income countries. Cochrane Database of Systematic Reviews, Issue 4. The Cochrane Collaboration: Hoboken, NJ. John Wiley \& Sons Ltd; 2009.

34. EPOS Health Management. Mid Term Review of the 'Development of the Health Sector (SWAp) Programme - Reproductive Health Voucher Scheme (Output Based Approach) in Kenya'. Bad-Homburg, Germany: EPOS Health Management; 2011.

35. World Health Organization (WHO). Global health expenditure database. Geneva: WHO. Available at: http://apps.who.int/nha/database/Select/ Indicators/en. Accessed April 18, 2013.

\section{Submit your next manuscript to BioMed Central and take full advantage of:}

- Convenient online submission

- Thorough peer review

- No space constraints or color figure charges

- Immediate publication on acceptance

- Inclusion in PubMed, CAS, Scopus and Google Scholar

- Research which is freely available for redistribution 